\title{
Compliance with a protocol for intrapartum antibiotic prophylaxis against neonatal group B streptococcal sepsis in women with clinical risk factors
}

\author{
Toni R. Sanders ${ }^{1,2}$, Christine L. Roberts ${ }^{3,4}$ and Gwendolyn L. Gilbert ${ }^{5,6}$ \\ ${ }^{1}$ Department of Public Health, University of Sydney, \\ ${ }^{2}$ Central Sydney Division of General Practice, Sydney, \\ ${ }^{3}$ NSW Center for Perinatal Health Services Research, Sydney, \\ ${ }^{4}$ School of Population Health and Health Services Research, University of Sydney, \\ ${ }^{5}$ Center for Infectious Diseases and Microbiology, Institute of Clinical Pathology and Medical Research, \\ Westmead Hospital, Sydney and \\ ${ }^{6}$ Department of Medicine, University of Sydney, Australia
}

Objective: The aim of this study was to determine the prevalence of clinical risk factors (CRF) for neonatal sepsis in laboring women and to evaluate clinician compliance with a CRF-based protocol for intrapartum antibiotic prophylaxis (IAP).

Methods: A retrospective chart audit was undertaken at a district hospital (A) and a tertiary obstetric hospital (B) in Sydney, Australia between 1996 and 1998, to determine compliance with IAP in women with defined CRF.

Results: Eighty-five (I2\%) women at Hospital A and II7 (I9\%) at Hospital B had one or more CRF. Overall compliance rates with the IAP protocols were 65 and $50 \%$ at Hospitals $A$ and $B$ respectively, but varied according to maternal, obstetric and sepsis-related risk factors. We postulate that differences between the hospitals were related to protocol implementation.

Conclusions: Compliance with a CRF-based protocol was lower than previously reported. Improvements in protocol development, implementation and maintenance are required to enhance compliance with IAP based on CRF.

Key words: Group B Streptococcus; Sepsis; Practitioner Compliance

Group B streptococcus (GBS) emerged approximately 25 years ago as the leading cause of neonatal sepsis. Before the introduction of preventative strategies the incidence of early-onset neonatal GBS sepsis was $1-2$ per 1000 births $^{1-4}$; the mortality, in a recent Australian study, was $10 \%{ }^{5}$. Most cases of neonatal GBS sepsis are preventable by intrapartum antibiotic prophylaxis (IAP) for women whose infants are at risk. Although the overall risk is relatively low - even for infants of GBS carriers - it is greater for infants whose mothers have clinical risk factors (CRF), such as prolonged rupture of membranes (PROM), prematurity or intrapartum fever $\geq 38^{\circ} \mathrm{C}^{2,6}$.

Several strategies have been proposed for a selection of women to receive IAP: GBS carriers

Correspondence to: T. R. Sanders, MPH, Level 1, 381 Liverpool Road, Ashfield NSW 2131, Australia.

Email: TSanders@csdgp.com.au

This study was supported by National Health and Medical Research Council grant number 974089 - screening pregnant women to prevent neonatal group B streptococcal sepsis. G. L. Gilbert, S. R. Leeder 
identified by routine antenatal vaginal and anal cultures; all women with CRF, irrespective of GBS carriage; or a combination of both ${ }^{3}$. The choice depends on costs, the proportion of cases and deaths that can be prevented, and the proportion of women to be given antibiotics ${ }^{3,6}$. Obviously, the success of the chosen strategy depends on compliance ${ }^{7}$. Theoretically, implementation of a carefully developed protocol should be straightforward but, in practice, factors such as workload or a poor understanding of the rationale of the

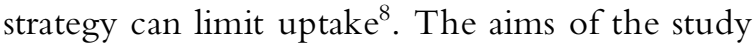
were to determine by a retrospective chart audit: (1) the prevalence of CRF for neonatal sepsis in women admitted to labor wards; (2) the rate of compliance with a protocol for IAP in women with CRF before and after a cohort study (in which compliance rates were compared between different IAP protocols based on GBS carriage, CRF or both; Gilbert and colleagues, manuscript submitted); and (3) the difference in factors affecting compliance between a community hospital and a tertiary obstetric center.

\section{METHODS}

\section{Background}

Because of potential differences in the incidence of risk factors in patients in different types of hospital, the study was undertaken in two public hospitals in Sydney, Australia; a district community hospital (2600 births pa, Hospital A) and a large tertiary obstetric center (4300 births pa, Hospital B) ${ }^{9}$. The metropolitan area served by these hospitals is a growing region with a young population, a diverse ethnic mix and relatively low socio-economic status ${ }^{10}$. It has a high birth rate and is predominantly serviced by public rather than private health care ${ }^{11}$.

\section{Protocol for intrapartum antibiotic prophylaxis}

Women with one or more CRF present on, or developed after, admission to the labor ward were to receive intravenous ampicillin 1 g every 6 hours until delivery (or erythromycin $500 \mathrm{mg}$ every 6 hours if there was a history of penicillin allergy). The CRF - determined by review of published literature ${ }^{3,6}$ - were: preterm labor $(<37$ weeks' gestation); PROM ( $\geq 18$ hours); intrapartum fever $\left(\geq 38^{\circ} \mathrm{C}\right)$; known vaginal colonization or urinary tract infection with GBS; or a history of a previous infant with GBS sepsis. Protocols were developed in consultation with local clinicians. There was formal and informal discussion with medical staff and midwives, and department heads formally supported the project.

\section{Study subjects and procedures}

All women were eligible for inclusion unless they had a planned Cesarean section, or were admitted to the labor ward less than 1 hour before delivery judged to be the minimum time required to implement IAP). A data extraction form was developed to document basic demographic data, obstetric and delivery details, the occurrence of CRF, and antibiotic doses given. Records were selected randomly (using a set number pattern) from those of all women who delivered during two study periods at each hospital. The protocol was implemented in July 1996 at Hospital A and July 1997 at Hospital B. Study periods (and approximate numbers of records reviewed) were July-December 1996 (500 records) and JanuaryJune 1998 (250) at Hospital A, and April-June 1998 (350) and July-September 1999 (350) at Hospital B. The review periods were chosen to assess whether compliance was affected by cohort studies conducted in the intervening periods, which compared compliance with different protocols based on GBS carriage, CRF, or both (Gilbert and colleagues, manuscript submitted).

Ethical approval for this study was granted by the Western Sydney Area Health Service Human Research Ethics Committee.

\section{Statistical analysis}

Associations were examined by frequency tabulations and contingency table analyses. Comparisons between the two hospitals and between time periods at each hospital were done using the chi-squared statistic or Fisher's exact test if the expected cell count was less than five. A $p$-value of 0.05 was considered statistically significant. Analysis was carried out using SAS Version 6.12 
for Windows. As there was no significant difference in population characteristics, GBS risk factors, or compliance between the two time periods at either hospital, the data were combined for each hospital.

\section{RESULTS}

A total of 1470 maternal records were reviewed 762 at Hospital A and 708 at Hospital B - of which 65 and 78, respectively, were excluded because the patients delivered by elective Cesarean section $(n=112)$ or admitted an hour or less before delivery $(n=31)$. There were no significant differences at either hospital between study periods, so data were pooled and compared between hospitals. Women at Hospital A were younger on average, and significantly more likely to be indigenous, unmarried and multiparous than those at Hospital B. Women at Hospital B were more likely to have one or more CRF for neonatal sepsis (Table 1). At both hospitals, women with CRF were more likely to have other markers of increased risk (Table 2) - first pregnancy, multiple pregnancy, non-cephalic presentation, fetal distress, or operative delivery. At Hospital A

Table I Maternal characteristics and clinical risk factors (CRF) for neonatal GBS sepsis by hospital

\begin{tabular}{lcc}
\hline & Hospital A & Hospital B \\
& $\mathrm{n}=697(\%)$ & $630(\%)$ \\
\hline Age* $<20$ years & $61(9)$ & $27(4)$ \\
Single* & $171(25)$ & $65(10)$ \\
Primaparous** & $256(37)$ & $272(43)$ \\
Indigenous & $33(5)$ & $6(1)$ \\
Clinical risk factors & & $1(0.2)$ \\
$\quad$ History of GBS UTI & $1(0.1)$ & $38(6)$ \\
Preterm birth & $31(4)$ & $79(13)$ \\
Prolonged rupture of membranes*** & $60(9)$ & $26(4)$ \\
Maternal fever* & $5(0.7)$ & $117(19)$ \\
Any risk factor** & $85(12)$ & $(19)$ \\
\hline
\end{tabular}

Significant differences between women at each hospital using $\chi^{2}$ tests, $* p<0.001$, $* * p<0.01, * * * p<0.05$; GBS, group B streptococcus; UTI, urinary tract infection

Table 2 Maternal and obstetric characteristics among women with and without clinical risk factors (CRF) by hospital (data are percentages)

\begin{tabular}{|c|c|c|c|c|}
\hline & \multicolumn{2}{|c|}{ Hospital A } & \multicolumn{2}{|c|}{ Hospital B } \\
\hline & $\begin{array}{c}\text { With CRF } \\
\mathrm{n}=85\end{array}$ & $\begin{array}{l}\text { No CRF } \\
\mathrm{n}=612\end{array}$ & $\begin{array}{c}\text { With CRF } \\
\mathrm{n}=117\end{array}$ & $\begin{array}{l}\text { No CRF } \\
\mathrm{n}=513\end{array}$ \\
\hline Indigenous & II & 4 & 0.8 & 1 \\
\hline Nulliparous* ${ }^{\dagger}$ & 59 & 34 & 61 & 39 \\
\hline Multiple pregnancy* ${ }^{\dagger}$ & 5 & 0.5 & 6 & 0.6 \\
\hline Induced/augmented labor ${ }^{\dagger \dagger}$ & 58 & 49 & 50 & 61 \\
\hline \multicolumn{5}{|l|}{ Cesarean section in labor or } \\
\hline instrumental delivery* ${ }^{\dagger}$ & 39 & 18 & 44 & 16 \\
\hline Noncephalic presentation $*^{\dagger}$ & 9 & 2 & 10 & 3 \\
\hline Fetal distress ${ }^{\dagger}{ }^{\dagger}$ & 60 & 45 & 59 & 41 \\
\hline Fetal scalp electrode* & 31 & 19 & 17 & 14 \\
\hline
\end{tabular}

Significant differences between women with and without CRF at each hospital using $\chi^{2}$ tests, Hospital A $* p<0.0$ I, **p $<0.05$; Hospital B ${ }^{+} p<0.01,{ }^{+} p<0.05$ 
Table 3 Compliance with intrapartum antibiotic prophylaxis (IAP) protocol by hospital, according to maternal and obstetric factors

\begin{tabular}{|c|c|c|}
\hline & $\begin{array}{c}\text { Hospital A } \\
\mathrm{n} *(\%)\end{array}$ & $\begin{array}{c}\text { Hospital B } \\
\mathrm{n} *(\%)\end{array}$ \\
\hline Overall compliance $^{\dagger}$ & $55 / 85(65)$ & $59 / 117(50)$ \\
\hline \multicolumn{3}{|l|}{ Onset of labor } \\
\hline Spontaneous & $17 / 36(47)^{\ddagger}$ & $25 / 58(43)$ \\
\hline Induced or augmented ${ }^{\dagger}$ & $38 / 49(78)$ & $34 / 59(58)$ \\
\hline \multicolumn{3}{|l|}{ Gestation } \\
\hline$<34$ weeks & $4 / 9(45)$ & $7 / 16(44)$ \\
\hline $35-36$ weeks & $10 / 22(46)$ & $8 / 22(36)$ \\
\hline$>37$ weeks $(\text { term })^{\dagger}$ & $4 I / 54(76)^{\ddagger}$ & $44 / 79(56)$ \\
\hline \multicolumn{3}{|l|}{ Mode of delivery } \\
\hline Spontaneous $^{\dagger}$ & $38 / 52(73)$ & $28 / 65(43)$ \\
\hline Instrumental delivery & $13 / 19(68)$ & $14 / 28(50)$ \\
\hline Cesarean section in labor ${ }^{\dagger}$ & $4 / 14(29)^{\ddagger}$ & $17 / 24(71)^{\ddagger}$ \\
\hline \multicolumn{3}{|l|}{ Presentation } \\
\hline Cephalic $^{\dagger}$ & $54 / 79(68)$ & $52 / 105(50)$ \\
\hline Noncephalic & $1 / 6(17)^{\ddagger \S}$ & $7 / 12(58)$ \\
\hline \multicolumn{3}{|l|}{ Fetal distress } \\
\hline Present & $35 / 5 I(69)$ & $42 / 69(6 I)$ \\
\hline Absent & $20 / 34(59)$ & $17 / 48(35)^{\ddagger}$ \\
\hline
\end{tabular}

*Data are number of women given IAP/number with any CRF $(\%)$; significant differences $(p<0.05)$ in the compliance with the protocol by $\mathrm{CRF}^{+}$between hospitals, ${ }^{\ddagger}$ between groups with and without in the same hospital; ${ }^{\S}$ numbers too small for meaningful interpretation

only, women with CRF were more likely to be indigenous and to have a fetal scalp electrode applied (Table 3).

Overall compliance with IAP among women with CRF was 65 and 50\% at Hospitals A and B, respectively. Women at Hospital A were more likely than those at Hospital B to receive IAP if labor had been induced or augmented, but less likely to if they had other features of high-risk pregnancy, especially Cesarean section in labor or a multiple birth. Compliance also varied by CRF for neonatal sepsis (Table 4). At both hospitals, it was highest for women with intrapartum fever, lowest for preterm labor, and intermediate for PROM. However, compliance was significantly higher at Hospital A than at Hospital B for women with PROM. The number of CRF identified did not affect compliance.

\section{DISCUSSION}

Compliance with a CRF-based protocol for IAP at the two Sydney hospitals was lower than in two previous reports ${ }^{12,13}$, but similar to that reported in a third, in which $65 \%$ of women with CRF during labor received antibiotics ${ }^{14}$. There was a significant difference in overall compliance rates between hospitals. The rate was lowest at Hospital A in women with preterm labor. Fleming and coworkers reported that non-compliance occurred at 35 and 36 weeks of gestation ${ }^{14}$, and attributed this to controversy over the appropriate cut-off for preterm labor. However, we found no difference in compliance for deliveries at $<34$ or at 35-36 weeks' gestation. At Hospital B, compliance was lowest when the indication was PROM. Traditionally, clinicians are taught that the risk of chorioamnionitis rises sharply 24 hours after rupture of membranes, so intervals of 18-24 hours may not seem significant ${ }^{14}$.

Non-compliance with the CRF-based protocol may be due to clinicians being distracted by other obstetric risk factors. Women with multiple pregnancies and those who required emergency Cesarean section, monitoring, or other interventions were generally more likely to have CRF 
Table 4 Compliance with intrapartum antibiotic prophylaxis (IAP) protocol by hospital according to individual clinical risk factor (CRF)

\begin{tabular}{lcc}
\hline & $\begin{array}{c}\text { Hospital A } \\
\mathrm{n}^{*}(\%)\end{array}$ & $\begin{array}{c}\text { Hospital B } \\
\mathrm{n}^{*}(\%)\end{array}$ \\
\hline Overall compliance $^{\dagger}$ & $55 / 85(65)$ & $59 / 117(50)$ \\
History of GBS UTI during pregnancy $^{\text {Preterm labor }<37 \text { weeks }}$ & $1 / 1$ & $1 / 1$ \\
Prolonged rupture of membranes $^{\dagger}$ & $15 / 31(48)$ & $15 / 38(40)$ \\
Maternal fever & $44 / 60(73)$ & $37 / 79(47)$ \\
Single CRF & $4 / 5(80)$ & $21 / 25(84)$ \\
Two CRF & $47 / 72(65)$ & $45 / 92(49)$ \\
& $8 / 13(62)$ & $14 / 25(56)$ \\
\hline
\end{tabular}

\footnotetext{
*Data are number of women given IAP/number with the CRF (\%); significant differences in the compliance of the protocol by CRF in women with and without GBS risk factors between hospitals using $\chi^{2}$ tests, ${ }^{+} p<0.05$; GBS, group B streptococcus; UTI, urinary tract infection
}

but less likely to receive IAP, although most already had intravenous access that would have made its administration easier. Compliance with protocols is also potentially compromised by the large number of clinicians involved in obstetric care in public hospitals. Fleming and co-workers ${ }^{14}$ found that any of 40 attending doctors might be involved in the care of women giving birth. The use of verbal orders to notify physicians of a CRF, despite standard written orders, is another possible reason for low compliance.

Women in this study could be identified as having a CRF only if it had been documented in the medical record, which is a limitation of retrospective audits. Cheon-Lee and colleagues ${ }^{12}$ found that non-compliance was related to poor documentation, especially of a previous infant with a GBS infection or maternal GBS bacteriuria. Less frequent recording was initially the suggested reason for the lower proportion of women with fever at Hospital A. However, discussion with staff indicated that temperatures were recorded every 2 hours at both hospitals. Hospital A used digital thermometers to measure sublingual temperatures. At the time, Hospital B used tympanic thermometers, which later were shown, anecdotally, to give abnormally high readings and were replaced by digital thermometers.

The difference in compliance between the two hospitals, despite similar protocols, suggests differences in motivation, implementation procedures, or both. The obstetric unit at Hospital A requested assistance with, and participated in the development of, the protocol. Staff at Hospital B developed their protocol independently. Involvement of senior staff in protocol development is essential to ensure that local factors are considered and that staff have ownership of the process. Grol and colleagues ${ }^{8}$ found that guidelines were more likely to be observed if they followed current practices and were not controversial. Allowing guidelines to be adapted at a local level should increase compliance. However, compliance was relatively poor at both hospitals in this study, despite the involvement of senior clinicians in protocol development.

Many studies have addressed the importance of local opinion leaders in the implementation of interventions ${ }^{15-18}$. The involvement of senior obstetric staff in implementation was limited in both hospitals, but in-service education and training of nursing and resident medical staff by the study team were undertaken at Hospital A but not Hospital B. More involvement of senior staff in the implementation and maintenance of the program may have improved compliance. Education should be tailored for different disciplines and presented by peers - senior medical staff to resident doctors and clinical nurse consultants to nursing staff ${ }^{19}$. Maintenance and improvement of protocol compliance would be facilitated by regular audits with feedback of results to clinicians ${ }^{20}$.

The use of triggers ${ }^{15,19}$ on patient observation sheets may also improve compliance; for example, a marker on the chart indicating the time at which 17 hours has elapsed since ROM and a red line on 
the temperature chart marking the 'fever threshold'. Women in labor could be assessed 15 hours after membranes had ruptured so antibiotic administration could be started if labor was expected to continue for 3 hours or more, although this could increase the number of normal women given IAP. Standing drug orders should be available to allow nursing staff to start IAP as soon as a CRF is identified, without waiting for a prescription to be written.

Clearly, protocol compliance was inadequate in both hospitals in this study, especially with respect to preterm labor and PROM, but full compliance is difficult to achieve. Some medical practitioners feel that protocols or practice guidelines reduce their professional autonomy and ability to offer individualized care, and may sacrifice the patient's well-being ${ }^{21}$. However, women have a right to be involved in their own treatment ${ }^{7}$ and, if informed of the indications for IAP, could collaborate with clinicians to improve protocol compliance. Whether or not it will be accepted will depend on the preferences of the caregivers, acceptability to consumers, ease of implementation, and costs.

\section{ACKNOWLEDGEMENTS}

The authors would like to thank Professor Stephen Leeder for assistance in the design and implementation of the overall study, Terry Leathers and Catherine Turner for their help in auditing records at both hospitals, and Moira Hewitt for help with data analysis in the initial stages of the study.

\section{REFERENCES}

1. Garland SM, Fliegner JR. Group B streptococcus (GBS) and neonatal infections: the case for intrapartum chemoprophylaxis. Aust $N Z J$ Obstet Gynaecol 1991;31:119-22

2. Schuchat A, Wenger JD. Epidemiology of group B streptococcal disease: risk factors, prevention strategies and vaccine development. Epidemiol Rev 1994;16:374-402

3. Gilbert GL, Isaacs D, Burgess MA, et al. Prevention of neonatal group B streptococcal sepsis: is routine antenatal screening appropriate? Aust $N Z \mathrm{~J}$ Obstet Gynaecol 1995;35:120-6

4. Schrag SJ, Zywicki S, Farley MA, et al. Group B streptococcal disease in the era of intrapartum antibiotic prophylaxis. N Engl J Med 2000;342:15-20

5. Isaacs D, Royle JA. Intrapartum antibiotics and early onset neonatal sepsis caused by group B streptococcus and by other organisms in Australia. Australasian Study Group for Neonatal Infections. Pediatr Infect Dis J 1999;18:524-8

6. Vigneswaran R, O’Loughlin JA, McDonald HM. Group B streptococcus and pregnancy. Aust $N Z J$ Obstet Gynaecol 1995;35:117-19

7. Yoong AFE, Lim J, Hudson CN, et al. Audit of compliance with antenatal protocols. $\mathrm{Br} \mathrm{Med} J$ 1992;305:1184-6

8. Grol R, Dalhuijsen J, Siep T, et al. Attributes of clinical guidelines that influence use of guidelines in general practice: observational study. $\mathrm{Br} \mathrm{Med} J$ 1998;317:858-61
9. NSW Health Department. New South Wales mothers and babies 1997. NSW Pub Health Bul Suppl 1998. State Health Publication number (EPI) 98019

10. Salked G, Chen T, Smith W, et al. Just health in western Sydney: an epidemiological profile of the people living in the western Sydney area health service. Western Sydney Area Health Service, 1992

11. Western Sydney Public Health Unit Health Needs of Western Sydney. Western Sydney Area Health Service, 1997

12. Cheon-Lee E, Amstey MS. Compliance with the centers for disease control and prevention antenatal culture protocol for preventing group B streptococcal neonatal sepsis. Am J Obstet Gynecol 1998; 179:77-9

13. Gibbs RS, McDuffie RS, McNabb F, et al. Neonatal group B streptococcal sepsis during 2 years of a universal screening program. Obstet Gynecol 1994;84:496-500

14. Fleming MT, McDuffie RS, Russell K, et al. Compliance with a risk-factor-based guideline for the prevention of neonatal group B streptococcal sepsis. Infect Dis Obstet Gynecol 1998;5:345-8

15. Oxman AD, Thomson MA, Davis DA, et al. No magic bullets: a systematic review of 102 trials of interventions to improve professional practice. Can Med Assoc J 1995;153:1423-31

16. Thomson MA, Oxman AD, Haynes RB, et al. Local opinion leaders to improve health 
professional practice and health care outcomes. The Cochrane Library 1998; Issue 2

17. Gifford DR, Holloway RG, Frankel MR, et al. Improving adherence to dementia guidelines through education and opinion leaders: a randomized controlled trial. Ann Intern Med 1999;131: 237-46

18. Davis DA, Thomson MA, Oxman AD, et al. Changing physician performance: a systematic review of the effect of continuing medical education strategies. J Am Med Assoc 1995;274:700-5
19. Bero LA, Grilli R, Grimshaw JM, et al. Getting research findings into practice: closing the gap between research and practice: an overview of systematic reviews of interventions to promote the implementation of research findings. $\mathrm{Br} \mathrm{Med} J$ 1998;317:465-8

20. Thomson MA, Oxman AD, Davis DA, et al. Audit and feedback to improve health professional practice and health care outcomes. The Cochrane Library 1998; Issue 2

21. DeMonaco HJ. Guidelines, pathways, and the end result. Crit Care Med 2000;28:889-90

ReCEIVED 03/15/02; ACCEPTED 05/30/02 


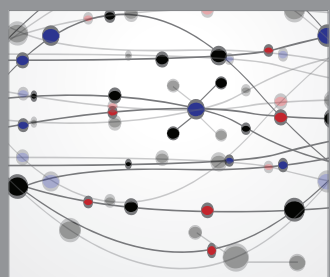

The Scientific World Journal
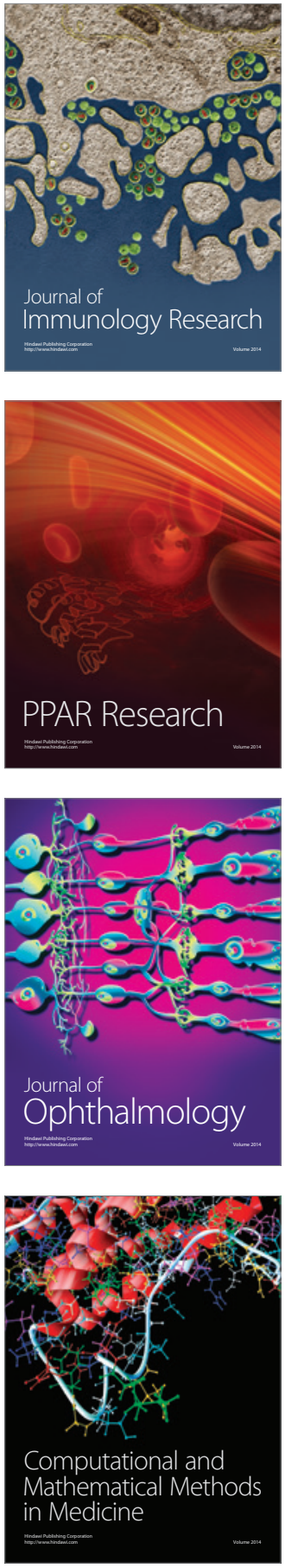

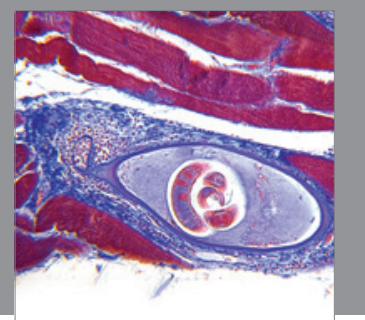

Gastroenterology

Research and Practice
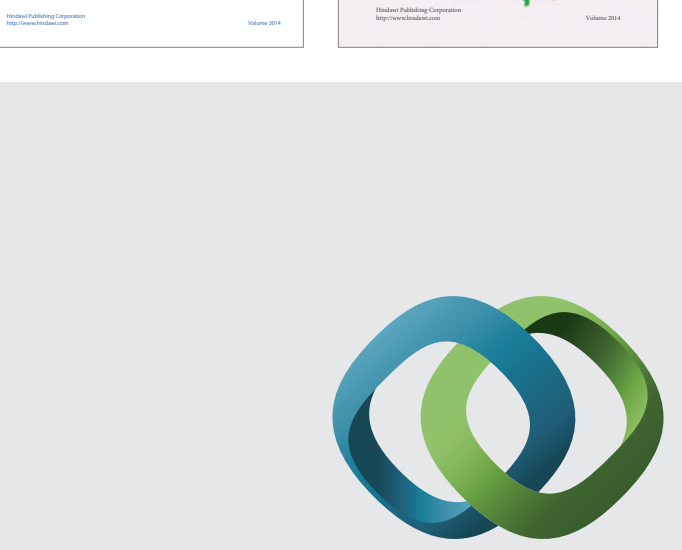

\section{Hindawi}

Submit your manuscripts at

http://www.hindawi.com
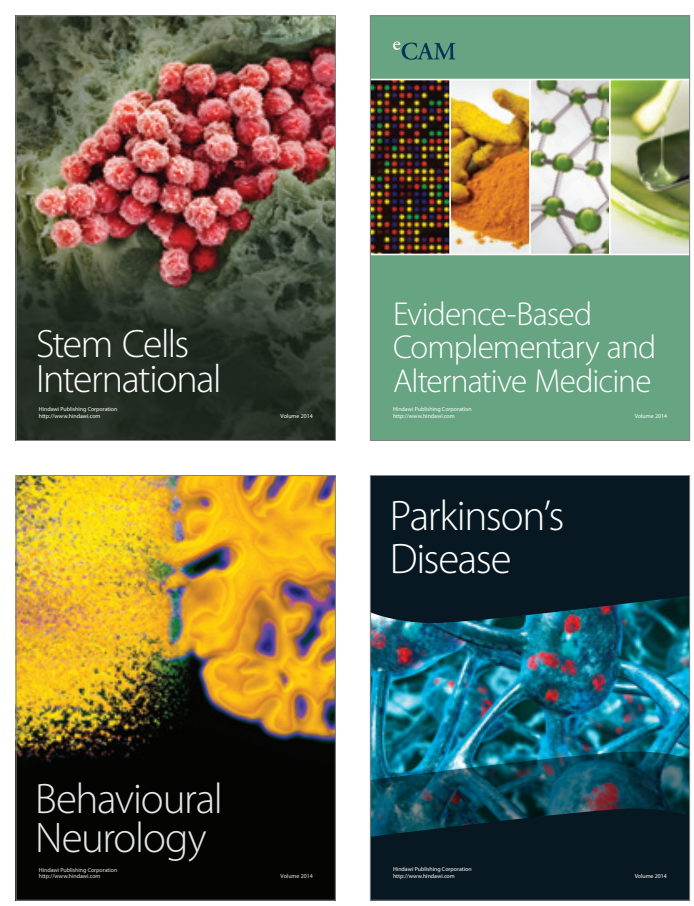

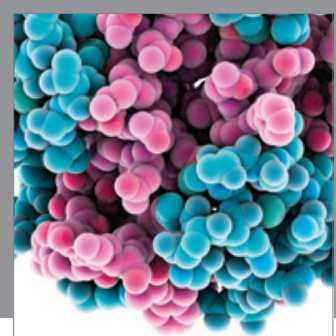

Journal of
Diabetes Research

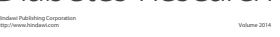

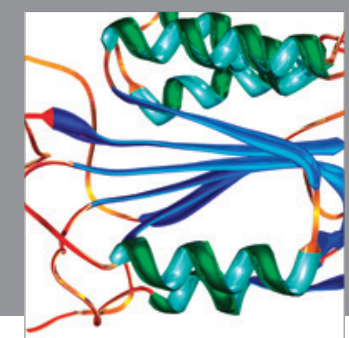

Disease Markers
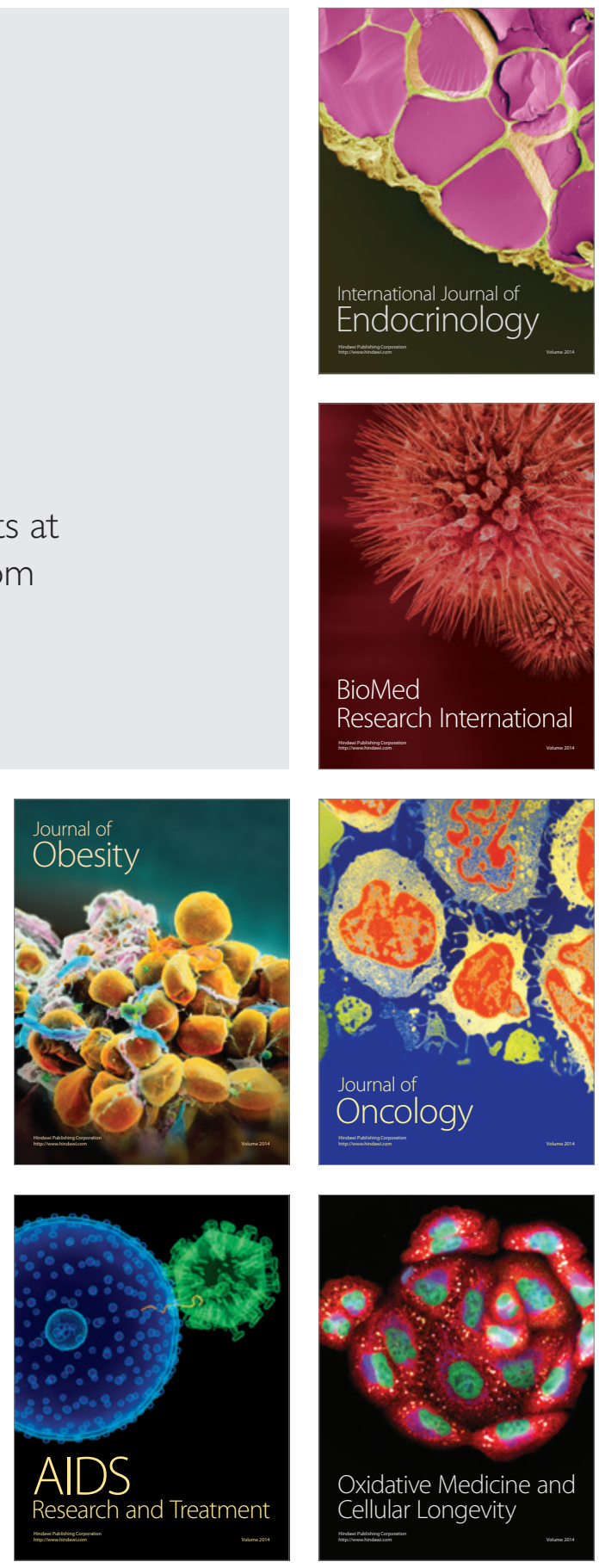